\title{
Accuracy of Frozen Section with Histopathological Report in an Institute
}

Purbesh Adhikari, ${ }^{\text {Paricha Upadhyaya, }}{ }^{1}$ Smriti Karki, ${ }^{1}$ Chandra Shekhar Agrawal, ${ }^{2}$ Shyam Thapa Chettri, ${ }^{3}$ Ajay Agrawal $^{4}$

'Department of Pathology, BP Koirala Institute of Health Sciences, Dharan, Nepal, ${ }^{2}$ Department of Surgery, BP Koirala Institute of Health Sciences, Dharan, Nepal, ${ }^{3}$ Department of Otorhinolaryngology and Head and Neck Surgery, BP Koirala Institute of Health Sciences, Dharan, Nepal, “'Department of Obstretics and Gynaecology, BP Koirala Institute of Health Sciences, Dharan, Nepal.

\section{ABSTRACT}

Introduction: Frozen section helps in rapid intra-operative diagnosis. It is commonly used during surgical procedures to detect malignancy so that modifications of surgery can be decided at the time of surgery on the table. Frozen section is also performed for evaluation of surgical margins and detection of lymph node metastasis. In addition it is applied for detection of unknown pathological processes.The objective of this study was to assess the accuracy of frozen section diagnosis in comparison to gold standard histopathological diagnosis and to find concordance and discordance rate of frozen section with histopathological report.

Methods: This was a cross sectional study of 41 frozen section samples done in the department of pathology of BP Koirala Institute of Health Sciences from September 2014 to August 2015. All frozen section samples with their permanent tissue samples sent for final histopathological evaluation were included in the study.

Results: The overall accuracy of frozen section diagnosis was $97 \%$. The sensitivity was $94 \%$, specificity was $87 \%$, positive predictive value was $90 \%$ and negative predictive value was $93 \%$. The concordance rate was $90.2 \%$ and the discordance rate was $9.8 \%$.

Conclusions: The results of frozen section varied in different organ systems and the common cause of discrepancy in our study were the gross sampling error and the interpretational error.

Keywords: accuracy; frozen section; sensitivity.

\section{INTRODUCTION}

Frozen section helps in rapid intra-operative diagnosis. ${ }^{1}$ It was first applied clinically in 1891 at Johns Hopkins Hospital by William Welch. ${ }^{2}$ It is performed during surgical procedures to diagnose malignancy, evaluation of surgical margins, detection of lymph node metastasis and unknown pathological processes. ${ }^{3}$

We conducted a comparative cross-sectional study on accuracy of frozen section in comparison to permanent histopathological sections which is the gold standard method of diagnosing pathological processes. One of the similar study conducted elsewhere in Nepal showed overall accuracy of frozen section to be $94.3 \% .^{4}$

The objective of this study was to compare the diagnostic accuracy of frozen section with permanent histopathological sections and also to find its concordance and discordance rate with the final histopathological report.

Correspondence: Dr. Purbesh Adhikari, Department of Pathology, BP Koirala Institute of Health Sciences, Dharan, Nepal. Email: purbeshadhikari@gmail.com, Phone:+977-9842168424. 


\section{METHODS}

It is a hospital based comparative cross-sectional study conducted in the Department of Pathology, BP Koirala Institute of Health Sciences from September 2014 to August 2015. Ethical approval for this study was provided by the Institutional Review Committee of B.P. Koirala Institute of Health Sciences. All the frozen section samples with their permanent tissue samples available for final histopathological evaluation were included in the study. We excluded the samples from the patients who denied for written informed consent. The frozen section diagnoses were correlated with the final histological diagnoses to assess the accuracy of frozen section diagnosis. The samples sent for frozen section and their permanent sections were received from elective surgeries performed in the Department of Obstretics and Gynaecology, Department of Surgery and Department of E.N.T. Samples for frozen section was sent in a container containing normal saline and the permanent tissue samples were sent in a container containing formalin to the histopathology lab at BP Koirala Institute of Health Sciences. Frozen section samples after submission were immediately grossed, frozen at a temperature of $-20^{\circ}$ celsius and sectioned on a cryostat machine (SLEE Cyrostat MNT) at 3-6 $\mu \mathrm{m}$ thickness. These sections were then stained by rapid Haematoxylin and Eosin method of staining. Frozen section reports were given within 20-30 minutes after submission of sample.

After receiving the permanent section, specimen was fixed in $10 \%$ formalin, grossed and adequate representative sections were taken, paraffin embedded and processed according to the standard guidelines and stained with conventional Haematoxylin and Eosin stain applied for permanent tissue sections. All the Frozen sections and final histopathological diagnoses were reported by consultant pathologist. After comparison with the final histopathological reports all the frozen sections were categorized into following operational categories.

Concordance: Concordance was described as an adequate intra-operative frozen section study and complete diagnostic agreement with the permanent section.

Discordance: Discordance was described as an adequate intra-operative frozen section study and diagnostic disagreement with the permanent study.

The discordance cases were studied further to determine the reasons for the discrepancies. The classification of errors were defined as follows:
1) Gross sampling error: The representative sampling from the lesion was missed during surgery.

2) Microscopic sampling error: The lesion was in the tissue which was sampled but was not revealed in the sections which were studied.

3) Interpretation error: The relevant tissue was in the frozen section slide, but the correct diagnosis was not made.

4) Failure of communication: The surgeon possessed information that probably would have changed the frozen section diagnosis, had it been communicated to the pathologist.

The statistical analysis was done in SPSS version 11.5 after entering the data in MICROSOFT EXCEL 2013. Descriptive variables were analyzed through frequency and proportion. The frozen section results were analyzed for sensitivity, specificity, positive predictive value and negative predictive value taking histopathology as gold standard method.

\section{RESULTS}

During the study period of one year, a total of 41 samples were received for frozen section analysis. The maximum number of sample received for frozen section was from gynaecology specimens accounting to 17 $(41 \%)$ of the total sample, followed by margins from different anatomical sites which was $6(15 \%)$ of the total sample (Table 1).

Table 1. Organs submitted for frozen section.

\begin{tabular}{|lc|}
\hline \multicolumn{1}{|c}{ Organ Submitted } & $\begin{array}{c}\text { No of cases } \\
\text { n (\%) }\end{array}$ \\
Gynaecology specimens & $17(41)$ \\
Margins & $6(15)$ \\
Gastro-Intestinal Tract & $5(13)$ \\
Thyroid & $3(7)$ \\
Nasal cavity & $2(5)$ \\
Parotid & $1(2)$ \\
Urinary bladder & $1(2)$ \\
Others & $6(5)$ \\
Total no of cases & 41 \\
\hline
\end{tabular}

The overall concordance rate in our study was 37 $(90.2 \%)$ and the discordance rate was 4 (9.8\%) (Table 2). 
Adhikari et al. Accuracy of Frozen Section with Histopathological Report in an Institute.

\begin{tabular}{|c|c|c|}
\hline Site & Concordant & Discordant \\
\hline \multicolumn{3}{|l|}{$\begin{array}{l}\text { Gynaecology } \\
\text { specimens }\end{array}$} \\
\hline Ovary & 15 & 0 \\
\hline Uterus & 2 & 0 \\
\hline Omentum & 1 & 0 \\
\hline Gastrointestinal & 5 & 0 \\
\hline Thyroid & 1 & 2 \\
\hline Salivary gland & 2 & 0 \\
\hline Lymph node & 1 & 1 \\
\hline $\begin{array}{l}\text { Tissue of } \\
\text { unknown origin }\end{array}$ & 0 & 1 \\
\hline Margins & 6 & 0 \\
\hline Others & 4 & 0 \\
\hline Total & $37 \quad(90.2 \%)$ & $4(9.8 \%)$ \\
\hline
\end{tabular}

The overall accuracy was $97 \%$ and the sensitivity and specificity were $94 \%$ and $87 \%$ respectively. False positive result in a single case of thyroid and in another case of female genital tract lesion resulted in a PPV of $90 \%$ and a false negative result in a lesion from thyroid resulted in a NPV of $93 \%$ as calculated from (Table 3 ).

\begin{tabular}{|llccc|}
\hline \multicolumn{1}{|l|}{$\begin{array}{l}\text { Table 3. Neoplastic vs non neoplastic lesions (total } \\
\text { number of cases). }\end{array}$} & \multicolumn{4}{c|}{ Final Diagnosis } \\
\hline \multicolumn{4}{|c|}{$\begin{array}{c}\text { Neoplastic } \\
\text { Non- } \\
\text { neoplastic }\end{array}$} \\
Frozen & Neoplastic & 18 & 2 & 20 \\
Section & Non- & 1 & 14 & 15 \\
Diagnosis & neoplastic & 1 & 16 & 35 \\
Total & & 19 & & \\
\hline
\end{tabular}

The sensitivity and specificity in obstetric and gynaecological lesion was $100 \%$ and $87.5 \%$ respectively. The low specificity was due to an interpretational error of a single case which was diagnosed as a neoplastic lesion on frozen section while the permanent histopathological diagnosis of the same case was rendered as Xanthogranulomatous lesion. The results of frozen section were discordant in two of the head and neck lesions in our study due to sampling error in one of the case and interpretation error in the other. The discrepancy in both the cases resulted from lesions in the thyroid. Two lymph nodes were received during the period of study. First case was correctly diagnosed as Metastatic deposits of carcinoma, but the second case was discordant because of the sampling error. Details of all four discordant cases are tabulated in (Table 4).

Table 4. Details of discordant cases.

\begin{tabular}{|c|c|c|c|c|c|}
\hline S.N & $\begin{array}{l}\text { Details of } \\
\text { sample for } \\
\text { frozen section }\end{array}$ & $\begin{array}{l}\text { Frozen } \\
\text { section } \\
\text { diagnosis }\end{array}$ & Final diagnosis & Type of error & Reason for discrepancy \\
\hline 1 & $\begin{array}{l}\text { Tissue from an } \\
\text { abdominopelvic } \\
\text { cyst }\end{array}$ & $\begin{array}{l}\text { Highly } \\
\text { suspicious } \\
\text { of malignant } \\
\text { lesion }\end{array}$ & $\begin{array}{l}\text { Xanthogranulo- } \\
\text { matous lesion }\end{array}$ & $\begin{array}{l}\text { Interpretation } \\
\text { error }\end{array}$ & $\begin{array}{l}\text { Cholesterol clefts with surrounding } \\
\text { inflammatory cells can be confused } \\
\text { with proliferating glands in frozen } \\
\text { section. Only cholesterol clefts will } \\
\text { look like empty space. }\end{array}$ \\
\hline 2 & $\begin{array}{l}\text { Cyst wall from } \\
\text { cystic lesion of } \\
\text { thyroid }\end{array}$ & Benign cyst & $\begin{array}{l}\text { Papillary } \\
\text { carcinoma of } \\
\text { thyroid }\end{array}$ & $\begin{array}{l}\text { Gross sampling } \\
\text { error }\end{array}$ & $\begin{array}{l}\text { Representative sampling for frozen } \\
\text { section was missed as the cyst } \\
\text { wall excised lacked any evidence of } \\
\text { papillary carcinoma of thyroid. }\end{array}$ \\
\hline 3 & $\begin{array}{l}\text { Tissue from left } \\
\text { lobe of thyroid }\end{array}$ & $\begin{array}{l}\text { Follicular } \\
\text { neoplasm }\end{array}$ & $\begin{array}{l}\text { Papillary } \\
\text { carcinoma of } \\
\text { thyroid }\end{array}$ & $\begin{array}{l}\text { Interpretation } \\
\text { error }\end{array}$ & $\begin{array}{l}\text { Diagnosis of Follicular neoplasm was } \\
\text { made on frozen section on the basis of } \\
\text { presence of thyroid follicles filled with } \\
\text { colloid and FNAC report of "Follicular } \\
\text { lesion of undetermined significance" in } \\
\text { the same case. }\end{array}$ \\
\hline 4 & Lymph Node & $\begin{array}{l}\text { Non-specific } \\
\text { lymphadenitis }\end{array}$ & $\begin{array}{l}\text { Kimura disease } \\
\text { of Iymph node }\end{array}$ & $\begin{array}{l}\text { Gross sampling } \\
\text { error }\end{array}$ & $\begin{array}{l}\text { Lack of representative sample from the } \\
\text { main lesion was regarded as the cause } \\
\text { of discrepancy since the other lymph } \\
\text { nodes processed after completion of } \\
\text { surgery showed evidence of Kimura } \\
\text { disease in the sections examined. }\end{array}$ \\
\hline
\end{tabular}


Adhikari et al. Accuracy of Frozen Section with Histopathological Report in an Institute.

Tissues from two salivary gland tumors and six margins of malignant tumors from different anatomical sites were correctly diagnosed by frozen section. Two salivary gland tumors were a case of mucoepidermoid carcinoma of left parotid gland and adenoid cystic carcinoma of right nasal cavity respectively. Out of six (6), five (5/6) margins were tissues of oral cavity. Four (4/5) of these tissues were diagnosed as a case of squamous cell carcinoma of oral cavity on permanent sections. Of the remaining two cases sent for frozen section evaluation of margins, one case was diagnosed as verrucous carcinoma of oral cavity on permanent section, the margins of which were negative on frozen section. The other case consisted of margins from a retroperitoneal soft tissue tumour later diagnosed as leiomyosarcoma on permanent section, the margins of the same were positive for tumor cells on frozen section. Two out of four (2/4) cases of squamous cell carcinoma had margins positive for tumour.

Total 15 ovarian tissues were received for frozen section analysis. Following were the diagnoses of these 15 cases:- three benign serous cystadenoma, one serous cystadenocarcinoma of bilateral ovaries, one borderline mucinous cystadenoma, one benign brenner tumour, three endometriotic cyst, two mature cystic teratoma, two salphingo-oophoritis. Out of the two remaining cases, in a case although the borderline nature of the ovarian tumor was correctly identified, the epithelial nature of the tumor could not be decided and it was later diagnosed as "Borderline mucinous cystadenoma " in permanent section. In another case cyst wall revealed inflammation only without any lining epithelium in both frozen section and permanent section.

A single case of choriocarcinoma was correctly diagnosed on frozen section. Three omental biopsies sent for frozen section analysis were correctly diagnosed of having metastatic deposits of adenocarcinoma. A tissue received from pancreatic cystic lesion was diagnosed as a benign lesion (suggestive of lymphoepithelial cyst of pancreas) on frozen section which was concordant with final histopathology report.

\section{DISCUSSION}

The total concordance rate of frozen section with histopathological reports in our study was $90.2 \%$ and the discordance rate was $9.8 \%$. In a similar study conducted by Fariba Abbasi and colleague in Iran the concordant rate was $74.5 \%$ which is slightly lower than our result and the discordant rate was $4 \%$ in their study which was lower than that in our study. ${ }^{5}$ The discrepancy in the diagnosis of two out of three thyroid lesions resulted in the higher rate of discordance in our study whereas in the study conducted by Fariba Abbasi, there were no discordant cases in all their five thyroid cases. ${ }^{5}$

The overall accuracy of frozen section in our study was $97 \%$ which is comparable with accuracy of frozen section reported in different studies which ranges from 91.5 to $97.4 \% .^{3,6}$ All the 15 ovarian samples were correctly diagnosed with no discrepancy. In our study except in three cases, in all the other remaining cases the whole of the tumour or cyst was sent for frozen section evaluation. Similarly in the study done by Sennur, in 590 out of 617 cases, the whole of the tumour or cyst was sent for frozen section evaluation. ${ }^{7}$ Taking representative samples for frozen section examination was easier in those cases since the entire tumour was available for evaluation. Studies claim that the diagnostic disagreement especially occurs in mucinous and borderline tumour groups..$^{8-10}$ The causes of discordant cases are most commonly due to sampling error, misinterpretation, lack of communication with the surgeons and technical problems. ${ }^{11}$ The sensitivity, specificity, positive predictive value and negative predictive value and accuracy were $100 \%, 87.5 \%$, $91.6 \%, 100 \%$ and $94.7 \%$ respectively in our study in gynaecological lesions which is comparable with studies done in other parts of the world. Since the time frame of this study was only one year, and samples received were limited, thus it was not possible to calculate the sensitivity and other parameters separately for benign, borderline and malignant lesions of ovary.

The status of frozen section as a cost effective tool in thyroid lesions has been debated because of increased operative time without true consensus. ${ }^{12}$ Most surgeons perform frozen section in thyroid lesions to confirm all diagnosis of neoplasia made by FNAC. ${ }^{13}$ In a study conducted in USA, the sensitivity and specificity of frozen section were $76.9 \%$ and $67.9 \%$ respectively and the PPV and NPV were $27.8 \%$ and $94.8 \% .{ }^{14}$ In our study we received only three cases of thyroid. So sensitivity and other parameters to determine the accuracy of frozen section in comparison to histopathology were not calculated. Out of these three cases, one case was correctly categorized as a case of Hashimoto's thyroiditis on histopathology. Among the two remaining cases, one case was categorized as discordant because of lack of representative sample by the surgeons since only the metaplastic squamous epithelium lining the cyst was sampled for frozen section evaluation. The final histopathology revealed multiple foci of squamous metaplastic lining epithelium within the cystic changes seen in a case of papillary thyroid carcinoma. Another case of thyroid was an interpretation error in frozen section which was diagnosed as "follicular neoplasm" in frozen section. FNAC report of "follicular neoplasm of undetermined significance" and the presence of thyroid follicles of uniform size misguided the diagnosing 
pathologists to determine the exact nature of the lesion which was diagnosed as "colloid nodule" when final histopathology report was dispatched.

In our study, a single case was diagnosed as suspicious of malignancy on frozen section in which cholesterol clefts seen in histopathological sections were misinterpretated as proliferation of glands lined by atypical cells in frozen section. Xanthogranulomatous reaction was the diagnosis considered in the final histopathology report as parent tissue could not be delineated and origin of the tissue could not be identified even on radiological evaluation because of its large size. Complete excision of the lesion was not possible since the origin of lesion could not be identified even on laparotomy.

Xanthogranulomatous inflammation is a form of chronic inflammation that is destructive to the normal tissue of affected organs. ${ }^{15}$ This lesion is documented in gall bladder, stomach, anorectal area, bone, urinary bladder, testis, epididymis, ovary, vagina and endometrium. ${ }^{19}$ Since we received this case from abdominopelvic region, female genital tract was likely to be the site of pathology. The clinical and radiological picture of xanthograunulomatous inflammation masquerades malignancy in most of the cases. So, preoperative frozen section can reveal the inflammatory pathology and help in proper management. Review of literature shows that even on frozen section xanthogranulomatous inflammation of pituitary i.e. Xanthogranulomatous hypophysisitis has been misinterpretated as pituitary adenoma. ${ }^{16}$ However, in female genital tract lesions there are evidences where malignancy have been ruled out on frozen section and diagnosis of inflammatory lesion with fibrosis has been rendered when such suspicious tissues were sampled for frozen section evaluation. ${ }^{16,17}$

Xanthogranulomatous inflammation often poses diagnostic challenge for pathologists because of its rarity. Both non neoplastic and neoplastic conditions are fielded in the differential diagnosis. ${ }^{18}$ Awareness of this inflammatory lesion can prevent cases from being falsely diagnosed as malignant and thereby undergoing a radical surgery where it is not necessary. ${ }^{19}$

Intra-operative frozen section analysis of margins is widely employed to assist in complete tumor extirpation. Lower local tumor recurrence rates and improved survival have been reported when tumor-free margins are achieved at the time of surgery. ${ }^{20}$ Failure to achieve clear margins reduces the chance of local control. ${ }^{21}$

We received total of six cases where margins from the suspected case of malignancy were sent for frozen section evaluation. All the margins were correctly typed in frozen section when compared with final histopathology report. Of the total five from oral cavity, four case were diagnosed as squamous cell carcinoma of oral cavity and a single case was diagnosed as verrucous carcinoma of oral cavity on final histopathology. Margins were positive for tumours on frozen section in two of the squamous cell carcinoma cases and negative in the remaining cases of oral cavity. In cases with positive margins on frozen section, they remained positive for tumours even after extended surgical resection. In the tumours where margins were negative for tumours on frozen section, surgeons had the advantage of limiting their field of excision and excise the tumour aptly.

Experience from other authors performing intraoperative frozen section evaluation of margins from head and neck cancers is also that although the frozen section margins are positive for presence of tumour, they cannot reliably eradicate positive final margins. ${ }^{20}$

Our experience with the frozen section examination of tissue margins is that the evaluation of re-excision margins of the tumour sometimes becomes difficult because the large size of a tumour may distort the normal anatomy resulting in improper orientation of the tissue margins. In such cases comparing original margins for frozen section and final margins after reexcision appears inappropriate. In such scenarios we recommend processing remains of the original tissue after frozen section with gold standard histopathological method and comparing it with the frozen section. The main indications for intra-operative consultation in the evaluation of gastrointestinal tract specimens are to evaluate the adequacy of resection (margin check), diagnosis (what is it?), and to evaluate the extent of disease (such as tumor spread). ${ }^{22}$

From the gastro-intestinal tract we received total five cases. The purpose of frozen section in these tissues was to diagnose the unknown pathological processes in some and to evaluate the margins for the presence of tumour in others. All the cases on frozen section showed atypical cells forming glands and tubules. On histopathology these cases were later diagnosed as adenocarcinoma of the involved organ (samples received were from stomach, duodenum, caecum and ileum). As noted in our study, the gastrointestinal tract was the site that was associated with less diagnostic discrepancies which is similar to findings in other studies. ${ }^{23-25} \mathrm{~A}$ single lymph node received for detection of metastatic deposits of adenocarcinoma of stomach on frozen section showed true positive results.

To conclude, the overall accuracy of our frozen section diagnoses is similar to that reported in the literature. Inaccurate diagnoses in our study was most frequently due to gross sampling error and interpretation errors. We also believe that determining the presence or absence 
Adhikari et al. Accuracy of Frozen Section with Histopathological Report at B.P.K.I.H.S.

of malignancy without subtyping it can be an option to decrease the discrepancies of frozen section diagnoses. Limitation of our study was the limited number of cases and the duration of the study because of which we were unable to calculate the accuracy of frozen section in all the organ system separately.

\section{CONCLUSIONS}

Frozen section is a very useful and accurate procedure which can be highly beneficial for the proper management of patients if careful inspection of the gross specimen, proper sampling of the lesion, attention to areas bearing possibility of interpretational error and good communication with the operating surgeons is maintained.

\section{Conflict of Interest: None.}

\section{REFERENCES}

1. Dankwa EK, Davies JD. Frozen section diagnosis : an audit. J Clin Pathol. 1985;38 (11):1235-40. [PubMed | Full Text]

2. El Bahrawy M, Ganesn R.Frozen section in gynaecology : uses and limitations. Arch Gynecol Obstet. 2014;289(6):1165-70. [PubMed | DOI | Full Text]

3. Kaufman Z, Lew S, Griffel B, Dinbar A. Frozen-section diagnosis in surgical pathology. A prospective analysis of 526 frozen sections. Cancer. 1986;57(2):377-9. [PubMed]

4. Shrestha S, Mc L, Dhakal H, CB P, Pradhan M, Basyal R, et al. Comparative Study of Frozen Section Diagnoses with Histopathology. Post Graduate Medical Journal of NAMS. 2009;9(2): 1-5. [Full Text]

5. Abbasi F. Accracy of Frozen Sections. Iranian Journal of Pathology.2012;7(1):3-8. [Full Text]

6. Wang KG, Chen TC, Wang TY, Yang YC, Su TH. Accuracy of frozen section diagnosis in gynecology. Gynecol Oncol. 1998;70(1):105-10. [PubMed DOI]

7. Ilvan S, Ramazanoglu R, Ulker Akyildiz E, Calay Z, Bese $\mathrm{T}$, Oruc N. The accuracy of frozen section (intraoperative consultation) in the diagnosis of ovarian masses. Gynecol Oncol. 2005;97(2):395-9. [PubMed|DOI]

8. Twaalfhoven FCM, Peters AAW, Trimbos JB, Hermans J, Fleuren GJ. The accuracy of frozen section diagnosis of ovarian tumors. Gynecol Oncol. 1991;41(3):189-2. [Full Text $\perp \mathrm{DOI}]$

9. Rose PG, Rubin RB, Nelson BE, Hunter RE, Reale FR. Accuracy of frozen-section (intraoperative consultation) diagnosis of ovarian tumors. Am J Obstet Gynecol. 1994;171(3):823-6. [PubMed]

10. Obiakor I, Maiman M, Mittal K, Awobuluyi M, DiMaio $\mathrm{T}$, Demopoulos R. The accuracy of frozen section in the diagnosis of ovarian neoplasms. Gynecol Oncol. 1991;43(1):61-3. [PubMed]

11. Usubütün A, Altinok $G$, Küçükali T. The value of intraoperative consultation (frozen section) in the diagnosis of ovarian neoplasms. Acta Obstet Gynecol Scand. 1998;77(10):1013-6. [PubMed]

12. Miller MC, Rubin CJ, Cunnane M, Bibbo M, Miller JL, Keane $\mathrm{WM}$, et al. Intraoperative pathologic examination: cost effectiveness and clinical value in patients with cytologic diagnosis of cellular follicular thyroid lesion. Thyroid. 2007;17(6):557-65. [PubMed | Full Text]

13. Anton RC, Wheeler TM. Frozen section of thyroid and parathyroid specimens. Archives of Pathology and Laboratory Medicine. 2005;129(12):1575-84. [PubMed]
14. Kahmke R, Lee WT, Puscas L, Scher RL, Shealy MJ, Burch WM, et al. Utility of Intraoperative Frozen Sections during Thyroid Surgery. Int J Otolaryngol.2013;2013:1-4. [Full Text]

15. Gray Y, Libbey NP. Xanthogranulomatous salpingitis and oophoritis: A case report and review of the literature. Arch Pathol Lab Med. 2001;125(2):260-3. [PubMed |DOI]

16. Aste L, Bellinzona M, Meleddu V, Farci G, Manieli C, Godano U. Xanthomatous hypophysitis mimicking a pituitary adenoma: Case report and review of the literature. J Oncol. 2010;2010:1-5. [Full Text]

17. Kalloli M, Bafna UD, Mukherjee G, Devi UK, Gurubasavangouda, Rathod PS. A Rare Xanthogranulomatous Oophoritis Presenting as Ovarian Cancer. Online J Health Allied Scs.2012;11(2):11. [Full Text]

18. ShuklaS,Pujani M,SinghSK, Pujani M. Xanthogranulomatous Oophoritis assciated with primary infertility and endometriosis. Indian J Pathol Microbiol. 2010;53:1978. [Full Text]

19. Karigoudar MH, Kushtagi AV, Karigoudar RM, Sirasagi A Xanthogranulomatous Oophoritis: A Rare Inflammatory Lesion. JKIMSU. 2013;2:111-5. [Full Text]

20. DiNardo LJ, Lin J, Karageorge LS, Powers CN. Accuracy, utility, and cost of frozen section margins in head and neck cancer surgery. Laryngoscope. 2000;110(10 Pt 1):1773-6. [PubMed]

21. Ribeiro NFF, Godden DRP, Wilson GE, Butterworth DM, Woodwards RTM. Do frozen sections help achieve adequate surgical margins in the resection of oral carcinoma? Int J Oral Maxillofac Surg. 2003;32(2):152-8. [Full Text]

22. Younes M. Frozen section of the gastrointestinal tract, appendix, and peritoneum. Arch Pathol Lab Med. 2005;129(12):1558-64. [PubMed]

23. Da Silva RDP, Souto LRM, Matsushita GDM, Matsushita MDM. Diagnostic accuracy of frozen section tests for surgical diseases. Rev Col Bras Cir. 2011;38(3):149-54. [PubMed]

24. Gephardt GN, Zarbo RJ. Interinstitutional comparison of frozen section consultations: A College of American Pathologists Q-probes study of 90538 cases in 461 institutions. Arch Pathol Lab Med. 1996;120(9):804-9. [PubMed]

25. Raab SS, Tworek JA, Souers R, Zarbo RJ. The value of monitoring frozen section-permanent section correlation data over time. Arch Pathol Lab Med. 2006;130(3):337-42. [PubMed] 